\title{
Aculturación en las fronteras de América. Cabeza de Vaca: el primer mestizo cultural
}

\author{
Alberto Prieto Calixto*
}

Resumen. El presente artículo aborda el tema del cautiverio presente en los Naufragios de Alvar Núñez Cabeza de Vaca (1542-1555). Los capítulos de cautiverio de Cabeza de Vaca se revelarán como la expresión de una pluralidad cultural que al mismo tiempo que humaniza al indígena, le concede voz, permitiéndole existir sin ser esclavo, bestia o cosa. Su narrativa cuestiona, por tanto, la voz autoritaria y autorizada del discurso colonial, llenando sus vacíos y omisiones, y remediando la visión reductora del indígena característica de la literatura de matiz imperialista. Palabras clave: Cabeza de Vaca, cautiverio, naufragios, conquista, aculturación

Abstract. This essay deals with the captivity ordeal that Alvar Núñez Cabeza de Vaca wrote in his autobiography Naufragios de Alvar Núñez Cabeza de Vaca (15421555). By means of the rethorical device of the anecdote, certain subversive situations to the order established by the official discourse are treated and Cabeza de Vaca is able to depict an overall positive and human image of his indigenous captors.

Keywords: Cabeza de Vaca, captivity, shipwrecks, conquest, acculturation

* Profesor asociado de literaturas y culturas hispánicas en Rollins College Winter Park, Florida, Estados Unidos. Correo electrónico: apcalixto@rollins.edu 
Según determinadas tendencias críticas, la producción literaria de finales del XVI aparece subordinada al servicio de un discurso de corte imperialista, centralista y monolítico que negaba la tolerancia y la integración entre culturas, promulgando un férreo orden absolutista. ${ }^{1}$ El cautiverio, en cuanto a su faceta de penetración de una cultura en otra, conforme a la línea del discurso oficialista de la corona, sería lo más cercano a la representación terrenal del infierno. En este tipo de descripción la frontera entre el yo, cautivo, católico, español, y el otro, captor, infiel, bárbaro, se manifiesta como algo drásticamente irreconciliable. $^{2}$

Para Beatriz Pastor (1988: 226) el "discurso mitificador de la conquista" es "una de las grandes coartadas del conquistador". En el discurso de dominación de la conquista, las relaciones entre el europeo y el hombre americano solían definirse exclusivamente en términos de sumisión y de esclavitud. Esta postura, de marcado sesgo etnocentrista, asume como punto de partida que la civilización es patrimonio del conquistador, en tanto la barbarie es condición sine qua non del indígena. Este discurso define, asimismo, como indica Pastor (1988: 226-227), "a los indígenas como salvajes bárbaros e inhumanos, justificando automáticamente la guerra que se les hace, la esclavitud que se les inflige, y el exterminio en masa que padecen en varios momentos de la conquista".

Para Homi Bhabha, en "The Other Question: Stereotype, Discrimination and the Discourse of Colonialism", incluido en The Location of Culture (1994: 71), el discurso colonial "is an apparatus that turns on the recognition and disavowal of racial/cultural/ historical differences [...] colonial discourse produces the colonized as a social reality which is at once an 'other' and yet entirely knowable and visible". Según Bhabha (1983: 198), "The objective of colonial discourse is to construe the colonized as a population of degenerate types on the basis of racial origin, in order to justify conquest and establish systems of

\footnotetext{
${ }^{1}$ Un ejemplo conocido de esta postura sería José María Maravall en La cultura del barroco (1975).

${ }^{2}$ La oposición teórica entre el "yo" (Self) y el "otro" (Other) parte del concepto de que el centro de la experiencia personal es un "yo" subjetivo que construye todo lo ajeno como lo "otro".
} 
administration and instruction". Algunos estudiosos contemporáneos del fenómeno del colonialismo y su representación textual argumentan que los escritores de este periodo rechazan el contacto cultural con el "otro". Así lo afirma Mary Louise Pratt (1986: 146), para quien estos escritores "were charged with installing the edifice of domination and legitimizing its hierarchy".

Este tipo de lecturas críticas responden a una interpretación global e ideológica, que intenta explicar el conjunto de la producción literaria de los siglos XVI y XVII como una configuración ideológica en bloque. Sería absurdo negar que existió una fuerte literatura propagandística al servicio de los intereses imperialistas de la monarquía. Sin embargo, estas posturas totalizadoras niegan la pluralidad de voces implícita en algunos textos y las contradicciones y fisuras que este discurso presenta en numerosas ocasiones.

En este sentido, los Naufragios de Alvar Núñez Cabeza de Vaca (15421555) y los episodios de cautiverio que en esta obra aparecen, se presentan como un ejemplo idóneo para demostrar una polifonía que no encaja en ningún tipo de interpretación de carácter absoluto. Pretendo verificar cómo las relaciones captor-cautivo difieren en múltiples ocasiones de esta visión monolítica. Además, me propongo escrutar de qué manera el cautiverio de Cabeza de Vaca invierte y desmitifica en parte el discurso imperialista de la corona. Prestaré especial atención a la representación que en el texto se ofrece sobre los captores, los efectos que produce la experiencia del cautiverio en los cautivos y las estrategias que éstos desarrollan para sobrevivir en un ambiente desconocido y hostil.

Los protagonistas de la visión épica de la conquista y del imperio son heroicos hombres de armas, como Pizarro o Cortés, capaces de sojuzgar vastos y poderosos imperios. ${ }^{3}$ El cautivo, según este esquema, se convierte en la antítesis del héroe épico. Jaime Concha (1986: 6), refiriéndose al caso del cautiverio americano, indica que: "náufrago, fugitivo, desertor, tránsfuga o prisionero -cualesquiera que sean las circunstancias que lo llevan a dejar su medio original- el cautivo insti-

\footnotetext{
${ }^{3}$ Un ejemplo de este tipo de discurso lo tenemos en el propio Hernán Cortés y sus Cartas de Relación (1519-1536).
} 
tuye una situación que es franca excepción en el panorama de la conquista y que resulta un escándalo en medio del naciente colonialismo".

En efecto, en los relatos de cautiverio la percepción de la historia y la participación individual en el proceso de la expansión del imperio, la conquista y la colonización alcanzan nuevas dimensiones. Ocurre, según se verá, que la tradicional relación "amo" -español-cristianoconquistador- "esclavo" -indígena-, se invierte, pasando estos últimos a asumir los papeles del primero. Conviene señalar que esta inversión no siempre es irreversible, y en ocasiones se produce una evolución que trasforma el rol del cautivo a lo largo de la cautividad. Al mismo tiempo, a medida que se prolonga la convivencia y se efectúa una gradual adaptación del cautivo cristiano a la cultura autóctona, aparece en algunos relatos una progresiva humanización del indígena americano.

Esta situación supone un amplio contraste con la visión deshumanizada que de estos "otros" presenta la literatura monolítica de corte imperialista de la corona. Este discurso de dominación y conquista participa de visiones como las de Gonzalo Fernández de Oviedo, compartida por muchos de sus contemporáneos, para quien, como observa Edmundo O'Gorman (1946: xvii-xviii): “los acontecimientos históricos de su época son la demostración palpable de la excelencia y superioridad de los españoles [...] [Oviedo] ve en esos acontecimientos el principio del cumplimiento de los altos fines históricos-universales del imperialismo, o sea, el logro de la unificación religiosa y política de todo el mundo bajo la corona española".

Para O'Gorman (1946: xvii-xviii), la visión utópica universalista de Carlos V corresponde a "una visión mesiánica de la historia, fundada en la inquebrantable fe que algunos españoles tenían en el destino providencial de su pueblo como el elegido de Dios para implantar la monarquía universal católica hasta la consumación de los tiempos".

Esta postura, en el caso americano, implica un concepto del indígena que justifica el trato que se le inflige durante la conquista. El mismo Oviedo propaga una determinada y tendenciosa visión del indígena recogida por Juan José Arrom (1983: 116): “Esta gente de su natural es ociosa y viciosa e de poco trabajo, e melancólicos e cobardes, viles y mal inclinados, mentirosos e de poca memoria e de ningu- 
na constancia. Muchos de ellos, por su pasatiempo, se mataron con ponzoña por no trabajar, y otros se ahorcaron por sus manos propias". Esta perspectiva considera al nativo como una especie de subhumano, inferior física, moral e intelectualmente. Se trata de hombres pero con unas características tan detestables que les degradan hasta el mundo irracional: "Son hombres, no bestias; pero tan viciosos, viles, cobardes, degenerados, supersticiosos, ingratos, falsos, perezosos y estúpidos que hay que tratarlos como a bestias. Ellos son los culpables de su propia destrucción por no ser capaces de formar parte del imperio católico de Carlos V"' (cit. en Anderson-Imbert, 1970: 28). De manera reveladora, el mismo Oviedo, que aquí a duras penas señala la condición humana del indígena, no puede evitar que se le escapen consideraciones respecto al indígena como la siguiente, al relatar las peripecias de un grupo de conquistadores en tierras venezolanas: "Allí tomaron algunos indios que llevaron adelante cargados con el oro y otras cosas, porque tenían mucha necesidad de bestias y porque ya no los matasen, ni convirtiesen, ni los dejasen libres, los tomasen por acémilas o asnos para llevar sus propios despojos, para quien se los tomaba" (cit. en Herren, 1992: 54; énfasis mío).

Circulaban, además de las de Oviedo, otras obras, tales como Elegía de varones ilustres de Indias (1589) de Juan de Castellanos, que denigraban al indígena americano y especulaban sobre su supuesta barbarie e inferioridad.

En este tipo de discurso, los españoles son representantes y portadores de una declarada superioridad cultural y moral. Los indígenas son, por el contrario, presentados sistemáticamente como bárbaros refractarios a la religión cristiana, abandonados a prácticas salvajes tales como la sodomía, los sacrificios humanos y el canibalismo. Sin embargo, tanto Oviedo como Cabeza de Vaca describirán instancias de canibalismo cometidas por españoles y no por indígenas, que chocan profundamente a estos últimos.

Los capítulos de cautiverio de Cabeza de Vaca se revelan como la expresión de una pluralidad cultural que al mismo tiempo que humaniza al indígena, le concede voz, permitiéndole existir sin ser esclavo, bestia o cosa. Su narrativa cuestiona, por tanto, la voz autoritaria y autorizada del discurso imperial, llenando sus vacíos y omisiones, y 
remediando la visión reductora del indígena característica de la literatura de matiz imperialista.

El texto de Cabeza de Vaca aparece publicado por primera vez en Zamora el año de 1542 bajo el título de "La relación que dio Alvar nuñez cabeça de Vaca de lo acaecido en las Indias en la armada donde yua por gouernador Panphilo de narbaez desde el año de veynte y siete hasta el año d'treynta y seys que boluio a Seuillla con tres de su compañia [sic]". Más tarde verá la luz en Valladolid en 1555 como "Relación y comentarios del gouernador Alvar Nuñez cabeça de vaca de lo acaescido en las dos jornadas que hizo a las Indias" [sic]. No será hasta 1749 en el tomo primero de Historiadores primitivos de las Indias Occidentales, donde aparezca bajo la hoy comúnmente aceptada denominación de Naufragios: Naufragios de Alvar Nuñez Cabeza de Vaca y relacion de la jornada que hizo a la Florida con el adelantado Panfilo de Narvaez [sic].

Nos encontramos en esta obra ante una narración donde historia y ficción aparecen enlazadas de manera intrincada. La hibridez de géneros constituye una nota destacada en este relato, que posee rasgos de relación, en el sentido más amplio del género, crónica histórica, documento antropológico y etnográfico, autobiografía, novelita de viajes, naufragios y peregrinación con matices mesiánicos, bizantinos, cautiverescos y hasta picarescos. Me centraré, de cara a mi análisis, únicamente en los aspectos que tienen que ver con el cautiverio en la obra de Cabeza de Vaca, aunque bien es cierto que éste ocupa prácticamente todo su relato. No en vano, y a pesar de los diversos estados y condiciones por los que Cabeza de Vaca se encuentra a lo largo de sus ocho años entre los indígenas, el explorador andaluz no deja de considerarse como cautivo durante todo este tiempo. En plena estancia con los indios, reflexionando sobre la ayuda que habían recibido de Dios, Núñez declara: "Y de mi sé dezir que siempre tuue esperança en su misericordia [de Dios] que me auía de sacar de aquella captiuidad"4 (1992: 254; énfasis mío). Cuando él y sus compañeros avis-

\footnotetext{
${ }^{4}$ Mantengo la grafía utilizada por Enrique Pupo-Walker en su edición de Los Naufragios publicada por Castalia en 1992 y que es la que manejo para este estudio.
} 
tan rastros de españoles, Cabeza de Vaca exclama: "dimos muchas gracias a Dios nuestro Señor por querernos sacar de tan triste y miserable captiuerio" (1992: 296; énfasis mío). Y casi al final del relato, explica, dirigiéndose al Rey, que en los "otros diez meses que después de salidos de captiuos sin parar anduuimos por la tierra no hallamos sacrificios ni ydolatría" (1992: 306; énfasis mío).

El cautiverio de Cabeza de Vaca y de sus compañeros en los Naufragios irrumpe en el capítulo XII, tras su fracasado intento de hacerse a la mar en la isla de Malhado para reunirse con el resto de la expedición de Narváez. Así, desnudos como nacieron, los encuentran de nuevo los indios. A pesar de que nada en el comportamiento de los indígenas lo presagie, en la mente de los españoles, avivada por aquellos que habían estado en la Nueva España, aparece el espectro del cautiverio y el sacrificio. Este temor aumenta dada la situación de desnudez que indica el desamparo total en el que ha acabado la desastrosa expedición de Narváez; poco a poco el grupo se ha visto desposeído de aquellos elementos que manifiestan su superioridad: naves, caballos, corazas, armas y vestimentas. El miedo de los náufragos a ser hechos cautivos aparece de este modo en el momento en que éstos se percatan de su vulnerabilidad simbolizada por la desnudez y la pérdida total de sus posesiones. El recelo de los españoles se revela aún menos justificado cuando los indígenas que acuden a socorrerles muestran tanta compasión al ver el estado en que se encuentran, que los propios cristianos se conmueven:

Los indios, de ver el desastre que nos auía venido y el desastre en que estáuamos, con tanta desuentura y miseria, se sentaron entre nosotros, y con el gran dolor y lástima que ouieron de vernos en tanta fortuna, començaron todos a llorar rezio, y tan de verdad, que lexos de allí se podía oyr, y esto les duró más de media hora; $\mathrm{y}$ cierto ver que estos hombres tan sin razón y tan crudos, a manera de brutos, se dolían tanto de nosotros, hizo que en mi y en otros de la compañía cresciesse más la pasión y la consideración de nuestra desdicha (1992: 221-222).

Por lo que vemos, Cabeza de Vaca y sus compañeros comparten todavía la concepción estereotipada de los conquistadores sobre el 
hombre americano que lo define como un ser "sin razón", "bruto", idólatra y adepto a costumbres bárbaras, tales como el sacrificio humano y el canibalismo, aunque por otro lado reconozcan en él sentimientos humanos como la solidaridad y la compasión.

Ignorantes sobre las costumbres de los nativos, y pese a la gentileza de éstos que les han llevado a su poblado y dado alojamiento, para los náufragos no hay "placer, fiesta ni sueño, esperando cuándo nos habían de sacrificar" (1992: 222). Sólo a la mañana siguiente, al persistir "tan buen tratamiento", asegura Alvar Núñez (1992: 222) que "nos aseguramos algo y perdimos algo el miedo del sacrificio".

Parte de la crítica ha reconocido la importancia y elaborado el tópico de la desnudez en la obra. Para Enrique Pupo-Walker (1987: 529530): "en los Naufragios la desnudez ciertamente alude a una drástica reducción de status y es, al mismo tiempo, como nuditas virtualis, el estadio que favorece reflexiones más sobrias y penetrantes sobre nuestra índole originaria" al mismo tiempo que nos evoca "ecos de la desnudez ascética". Sylvia Molloy (1987: 432) afirma que la desnudez de Alvar Núñez "distinguirá a una nueva persona" y que "desnudo, el yo sería una suerte de espacio despojado (España ha quedado atrás) que se irá llenando con lo desconocido -América- hasta lograr nuevo ser, nueva identidad". La "desnudez y el aprendizaje del otro que configuran al nuevo yo no se viven fácilmente". Añade Molloy que "esta desnudez física -primer alejamiento de lo propio, primera transgresión de un código que se va desechando- sorprende fuertemente al espectador, sea indio o cristiano, contrariando sus previsiones". Por ello no sorprende que los indígenas que han visto previamente a los españoles vestidos reaccionen fuertemente cuando los descubren desnudos, de igual manera que se sorprenden Dorantes y Castillo al ver a sus compañeros en tal estado. ${ }^{5}$ Beatriz Pastor (1989: 139-140), por su parte, propone que "the nudity metaphorically expresses the end of a process of liquidation that has gradually stripped the narrator of the attributes of the European conqueror, which amounts to a symbolic

\footnotetext{
${ }^{5}$ El mismo estupor muestran los hombres de la expedición de Cortés frente a la aparición de Aguilar como indio, o la de Hernando de Soto ante Juan Ortiz, apresurándose a entregarles las pocas vestimentas europeas que pueden recoger.
} 
death". A la vez añade que: "the state of primitive nudity from which this conqueror, now converted into mere man, will learn to see and know the new reality with new eyes, obliged by a situation of vulnerability that excludes the use of force as an instrument of control, putting him at the mercy of nature and the inhabitants of the New World". ${ }^{9}$ La desnudez presagia un cambio de status para los conquistadores españoles, previo a la inversión de papeles que se produce posteriormente cuando se encuentren ya cautivos de facto de los indígenas.

El cautiverio de Alvar Núñez y de sus compañeros no es repentino, sino progresivo. En primera instancia los indígenas, que ignoran el propósito de conquista de los españoles, tratan a los náufragos ni más ni menos como a huéspedes en dificultad. ${ }^{6}$ Se manifiesta en estos momentos una precaria ecuación de igualdad entre el indígena y el español, hecho este propiciado por la desnudez. Este inestable equilibrio tiene como base la subsistencia, que se presenta desfavorable para los españoles desnudos y vulnerables en un medio ambiente inhóspito, que diezma incluso a los propios indígenas de la isla. Consecuentemente, su presencia en la Isla de Malhado como huéspedes no puede seguir siendo tolerada. El cambio de status de los españoles se concreta y la inversión de papeles conquistador-conquistado comienza a manifestarse. En un primer momento, los indígenas demandan de los españoles que sean útiles. A partir de ahora su supervivencia va a depender de su utilidad. La condición de cautivos de los náufragos empieza a perfilarse de manera clara. Se ha modificado el modelo que ha persistido desde el primer contacto entre el español y el indígena en la isla de Malhado. Según este esquema, el nativo era designado como proveedor de grado o de fuerza de los europeos.

La importancia del papel que desempeña la utilidad de los españoles para su propia supervivencia es subrayada por Molloy (1987) quien le atribuye igualmente una función integradora dentro de la comunidad. Refiriéndose a las dos ocupaciones que desempeñará Cabeza de

\footnotetext{
${ }^{6}$ Por otro lado, su primer encuentro ha sido pacífico y sellado bajo el signo de la amistad con el usual intercambio de regalos. Los nativos no temen y no pueden temer a hombres que carecen de armas, caballos y ropa.
} 
Vaca durante su viaje (vendedor ambulante y médico viajero), Molloy (1987: 472) indica que no son casuales sino que "constituyen un intento de integrar al español en su sistema, adjudicándole una función útil dentro de su economía". Nótese el tono implícito al final de esta cita de los Naufragios: "ellos curan las enfermedades soplando al enfermo y con aquel soplo y las manos echan dél la enfermedad, y mandáronnos que hiziéssemos lo mismo y siruiéssemos en algo" (Cabeza de Vaca, 1992: 229; énfasis mío). La ocupación de los españoles como mercaderes es considerada por Silvia Spitta (1993: 319) como "la primera vez que vemos en las crónicas un trueque de igualdad entre un español y un indio" (319). Esta "igualdad" resulta un tanto sospechosa; los náufragos no aceptan sus nuevos puestos de buen grado; de hecho se les hambrea para que actúen como curanderos. Los españoles, subordinados a los indígenas, no tienen otro remedio que aceptar las ocupaciones que se les ofrezcan. Desde este momento se cierra el ciclo que los ha llevado de conquistadores a huéspedes y de huéspedes a cautivos.

El cautiverio presente en los Naufragios, lejos de ser algo establecido y concreto, como podría ser un baño argelino, o el banco de una galera, presenta múltiples facetas en las cuales el status del cautivo evoluciona, emulando el peregrinaje de los protagonistas y alcanzando notables diferencias respecto al captor, desde la sumisión hasta la superioridad, pasando por la igualdad.

La primera etapa de esta cautividad coincide con los años sedentarios de Cabeza de Vaca y sus compañeros. Esta inmovilidad confiere dureza al cautiverio. El cautivo se encuentra en un estado de vulnerabilidad total: carece de autonomía, padece humillaciones y está sometido a la voluntad y arbitrariedad de sus raptores. Los camaradas de Núñez no son ni más ni menos que esclavos de los indios: "esclauos, aunque estando siruiéndoles fueron tan maltratados dellos, como nunca esclauos ni hombres de ninguna suerte lo fueron, porque, de seys que eran, no contentos con darles muchas bofetadas y apalearlos y pelarles las baruas por su passatiempo, por sólo passar de vna casa a otra mataron tres" (Cabeza de Vaca, 1992: 241). La propia situación de Alvar no es mucho mejor: durante más de un año ha permanecido entre los indígenas de Malhado en calidad de esclavo, por lo que decide escaparse: 
[...] por el mucho trabajo que me dauan y mal tratamiento que me hazían, determiné de huýr dellos [...] porque yo no podía sufrir la vida que con estos otros tenía, porque entre otros trabajos muchos, auía de sacar las raýzes para comer debaxo del agua y entre las cañas donde estauan metidas en la tierra; y desto traýa yo los dedos tan gastados, que vna paja que me tocasse me hazía sangre dellos y las cañas me rompían por muchas partes, porque muchas dellas estaban quebradas (Cabeza de Vaca, 1992: 232-233).

Lo que queda de la expedición de Narváez aparece indefensa y vulnerable. Aislados y sedentarios, su cautiverio tiene mucho de esclavitud a la merced del capricho de sus captores. A partir de aquí presenciamos un insólito proceso en el que los españoles alternarán fases de dura esclavitud con periodos de relativa bonanza ocupados en sus actividades de físicos y mercaderes. En su ocupación de vendedor ambulante, Cabeza de Vaca mejora considerablemente sus condiciones de vida; tiene qué comer y, más importante aún, posee libertad de movimiento. La autonomía para ir de un lado a otro actúa como bálsamo reparador de la cautividad. A medida que este desplazamiento se detiene, las condiciones del cautiverio empeoran. Así, ante este parón, nos encontramos de nuevo a Núñez de la siguiente manera: “en este tiempo yo passé muy mala vida ansí por la mucha hambre como por el mal tratamiento que de los indios rescibía, que fue tal que yo me huue de huyr tres vezes de los amos que tenía" (Cabeza de Vaca, 1992: 246). ${ }^{7}$

El cautiverio en los Naufragios se va metamorfoseando progresivamente. La sumisión a manos de indios deja paso a otro tipo de cautividad. El captor deja de ser el indígena, con el que se establece cierta relación de igualdad e intercambio, y se convierte en otro más colosal si cabe por lo descomunal y desconocido: el medio hostil. Los víncu-

\footnotetext{
${ }^{7}$ Este "vaivén jerárquico" ha sido observado por Molloy (1987: 439), quien sugiere de manera satisfactoria que estas transformaciones se deben a la percepción que del español tenían los indígenas, considerándole como básicamente diferente, y ubicándole por tanto indistintamente en el extremo del privilegio o del sometimiento, allí donde resultara más útil.
} 
los entre españoles e indígenas empiezan a mostrar indicios del cambio sufrido, a la vez que crece la autoridad y el poder que los primeros ejercen sobre los últimos.

Una faceta importante de la experiencia del cautiverio en los Naufragios es que da lugar a un proceso de transformación interior que conlleva un cuestionamiento de los supuestos culturales y políticos que sustenta el cautivo. Varios estudiosos concuerdan en reconocer, con algunas variantes, este aspecto, ya sea como Invernizzi (1986: 24), al hablar de un "proceso de transformación interior, de viaje de iniciación, separación y retorno al origen, consagrado por la prestigiosa tradición del relato del viaje mítico del héroe que tiene su modelo en Ulises"; Lagmanovich (1978), para quien se trata de un viaje no sólo geográfico sino espiritual; un "viaje de aprendizaje y purificación" para Rivera Martínez (1993: 312), o "a journey that is at once a physical and spiritual odissey" según Nanfito (1994: 186). Apreciaciones cuya esencia comparten igualmente críticos ya citados como Molloy o PupoWalker.

El proceso de iniciación, de apertura de Cabeza de Vaca y sus compañeros hacia una realidad desconocida, los convierte no sólo en observadores de ésta, sino en parte misma de esta realidad. Es cierto que esta aculturación puede ser tan sólo una medida de supervivencia, pues desde el principio Núñez deja claro su deseo de volver a la civilización europea.

Un rasgo de esta aculturación, ampliamente tratado por la crítica, es la comida. Las transgresiones y modificaciones de las costumbres alimenticias señalan, más que una adaptación, una integración a lo ajeno como parte de los recursos del cautivo para sobrevivir. ${ }^{8}$

Íntimamente vinculada a la búsqueda de alimentos y a la adaptación de una nueva dieta como medio de supervivencia para el cautivo, surge la necesidad de observar y conocer a fondo las tierras que recorre. En los Naufragios la caracterización del medio es presentada de manera objetiva, sin que por ello deje escapar la oportunidad para

\footnotetext{
${ }^{8}$ El hambre también aparece en la mayor parte del peregrinaje de Cabeza de Vaca como el motor principal de su empresa.
} 
que se entiendan las riquezas que supondrían estas tierras si estuvieran en buenas manos, es decir, si fueran parte de la corona. Con ojos de europeo, Núñez contempla las grandes praderas aún intactas: "Por toda la tierra ay muy grandes y hermosas dehesas, y de muy buenos pastos para ganados, e parésceme que sería tierra muy fructífera si fuesse labrada y habitada de gente de razón" (Cabeza de Vaca, 1992: 247).

La visión del indígena presente en el relato de Cabeza de Vaca difiere de la descrita en el discurso de los conquistadores. No en vano, asistimos a una subversión de los papeles amo/esclavo, reflejo de la dicotomía civilización/barbarie, donde el primer apartado se reserva al conquistador y el segundo al indígena. La apreciación reductora que de los indígenas tenía al principio Cabeza de Vaca -recuérdense sus anteriores comentarios "tan sin razón y tan crudos, a manera de brutos" (1992: 221)- se va matizando a medida que transcurre su integración como cautivo en las sociedades americanas. Desde el principio, al detener su mirada sobre la apariencia física del indígena, Cabeza de Vaca (1992: 203) no escatima elogios hacia su apostura, fuerza y destreza: "Es gente a marauilla bien dispuesta, muy enxutos y de muy grandes fuerças y ligereza. Los arcos que vsan son gruessos como el braço, de onze o doze palmos de largo, que flechan a dozientos passos con tan gran tiento, que ninguna cosa yerran". Sus descripciones contrastan fuertemente con las grotescas figuras pintarrajeadas de los indios flecheros de la Nueva Granada que pinta Oviedo (cit. en Arrom, 1983: 117): “Tampoco tienen las cabezas como otras gentes, sino de tan recios e gruesos cascos que el principal aviso que los cristianos tienen cuando ellos pelean e vienen a manos, es no darles cuchilladas en la cabeza, porque se rompen las espadas. Y así como tienen el casco grueso, así tienen el entendimiento bestial y mal inclinado".

A lo largo de los Naufragios asistimos a un proceso de humanización hacia el hombre americano. Estos indios serán "la gente del mundo que más aman a sus hijos y mejor tratamiento les hazen" (Cabeza de Vaca, 1992: 226). Aun en momentos adversos de su cautiverio, Cabeza de Vaca (1992: 286) persiste en reconocer la prestancia del nativo: “Es la gente de mejores cuerpos que vimos, y de mayor viueza e habilidad", y en alabar su temple en la guerra: "Toda es gente de guerra y tienen 
tanta astucia para guardarse de sus enemigos como ternían si fuessen criados en Ytalia y en continua guerra" (Cabeza de Vaca, 1992: 264).

Ahora bien, no por esto se puede afirmar que Cabeza de Vaca (1992: 278) presenta una visión idealizada del indígena. En ocasiones da muestras de impaciencia frente a sus hábitos, como el de robarse los unos a los otros, que da título al capítulo veintinueve, o el de falsear: "son grandes amigos de nouelas y muy mentirosos, mayormente donde pretenden algún interesse". El soldado andaluz es consciente de la diversidad de los grupos indígenas en lo que se refiere a costumbres e idiosincrasia. Núñez no cae en generalizaciones al respecto, debido también en parte a que su supervivencia depende en gran medida del conocimiento real que adquiere sobre el indígena. Así, por ejemplo, evita atravesar las sierras de determinado territorio porque "toda la gente della es muy mala; y teníamos por mejor atrauessar la tierra, porque la gente que está más metida adentro, es más bien acondicionada y tratáuannos mejor" (Cabeza de Vaca, 1992: 275-276). A lo largo de sus Naufragios, incluso en las condiciones de vida más rudimentarias y extremas, Cabeza de Vaca reconoce la humanidad del hombre americano, su captor. En ocasiones se maravilla de su capacidad creadora, común a todo el género humano. Frente a los indígenas que carecen de utensilios de barro, reconoce el ingenioso modo que utilizan para cocinar sus alimentos: "la manera de cozerlas es tan nueua, que por ser tal, yo la quise aquí poner, para que se vea y se conozca quan diuersos y estraños son los ingenios e industrias de los hombres humanos" (Cabeza de Vaca, 1992: 287; énfasis mío). La doble cualidad otorgada aquí al indígena americano, hombre y perteneciente al género humano, es algo que no abunda en las crónicas de la época, donde se considera a menudo al nativo como una suerte de sub-hombre grotesco, vil, degenerado, idólatra y despreciable.

Mientras el nativo, captor, es presentado con rasgos patentes de humanidad, es el español el que frecuentemente pierde esta característica. Esta inversión de papeles la observamos en los episodios de canibalismo presentes en el texto. El canibalismo es un acto considerado como aberrante y antinatura, que por tanto niega la humanidad de quien lo realiza. Según Harriet Goldberg (1997: 109): “Because cannibalism is the ultimate hostile act that the human creature can 
inflict on another, it is clearly an act outside the usual limits of human behavior". El primer acto de antropofagia relatado no es cometido por los indios, sino por los españoles: "cinco christianos que estauan en rancho en la costa llegaron a tal estremo, que se comieron los vnos a los otros, hasta que quedó vno solo, que por ser solo no huuo quien lo comiesse" (Cabeza de Vaca, 1992: 225). ${ }^{9}$ Además del sorprendente hecho de que sean los cristianos los que practican el canibalismo, para mayor ironía, este suceso espanta sobremanera, más que a los propios españoles, a los indígenas: "Deste caso se alteraron tanto los indios, y ouo entre ellos tan gran escándalo, que sin dubda si al principio ellos lo vieran, los mataran, y todos nos viéramos en grande trabajo" (Cabeza de Vaca, 1992: 225).

Los episodios de antropofagia no debieron escasear durante el periodo de la conquista, aunque por lo general se circunscribían a casos de indígenas devorando a miembros de sus propias comunidades (endocanibalismo) o personas ajenas a su grupo (exocanibalismo), entre los que se encontrarían los europeos. La existencia de exocanibalismo entre los españoles hacia los indígenas es un hecho probado. ${ }^{10}$ Estos sucesos estaban probablemente facilitados por la circunstancia de que muchos de los españoles consideraban a los indios como subhumanos; una especie a caballo entre el hombre y la bestia. ${ }^{11}$ Sin embargo los hechos descritos por Cabeza de Vaca constituyen flagrantes ejemplos de endocanibalismo entre los propios españoles. Es éste un caso de extraordinaria relevancia. Su carácter subversivo, premeditado o no, resulta obvio: a la barbarie española del cautivo se opone la humanidad del captor indígena.

Pero, ¿cómo pudo pasar desapercibida a los ojos de la censura tal representación? Pupo-Walker, en nota a pie de página de su edición

\footnotetext{
${ }^{9}$ El segundo caso de canibalismo aparece en el capítulo XVII. “Y los que morían los otros los hazían tasajos, y el último que murió fue Sotomayor; y Esquiuel lo hizo tasajos y comiendo dél se mantuuo hasta primeros de Março" (Cabeza de Vaca, 1992: 239).

${ }^{10}$ Véase por ejemplo el caso del capitán Vascuña y sus hombres perdidos en la selva venezolana, narrado por Oviedo y recogido por Herren (1992: 47-63).

${ }^{11} \mathrm{He}$ reproducido con anterioridad algunas de las citas de Oviedo respecto al supuesto carácter subhumano del indígena.
} 
de Los Naufragios (Cabeza de Vaca, 1992: 225, nota 309), apunta que éste es uno de los pocos casos en que una relación autorizada documenta explícitamente un "grotesco episodio de canibalismo perpetrado por españoles entre ellos mismos". Efectivamente, hay algo de grotesco, de risa macabra en estos pasajes. Para Goldberg (1997: 103) "laughter serves to relieve the discomfort generated by the experience of thinking about the unthinkable". En realidad, la mayoría de los casos de antropofagia literaria suelen ir de la mano de esta risa siniestra. Probablemente este hecho contribuyó a camuflar el matiz subversivo de la situación. Una segunda explicación parte de la propia envoltura que se utiliza para relatar estos acontecimientos. Se trata de anécdotas microscópicas, en el caso de Esquivel, contada por otros, lo que les otorga cierto aire legendario. Estas anécdotas, consideradas los márgenes de la historia, poco más que una inserción ociosa, perdían, debido a su propia naturaleza, su significado histórico y formal. De este modo podrían pasar desapercibidas situaciones que de otra manera habrían resultado intolerables. Esto, al margen de que haya sido diseñado conscientemente o no por el narrador, es lo que el texto propone bien a las claras.

A Cabeza de Vaca se le ha querido ver como portavoz de posturas ideológicas y políticas, equiparando su actitud apologética de los indios a la del padre Bartolomé de las Casas. Se le ha presentado como "desmitificador de la conquista" y a su obra como ejemplificadora del "discurso del fracaso". ${ }^{12}$ Para Beatriz Pastor (1989: 136), máxima exponente de esta visión: "the demystifying character of his Naufragios seems to break the limits of the discourse of domination, making way for a criticism of the conquest and a presentation of the American reality that characterizes it in its own terms".

No se puede negar que el discurso narrativo de los Naufragios otorga voz al indígena y a su cultura, puesto que constituye el producto de una experiencia personal vivida desde el interior de la realidad americana. La voz autóctona, aun a través de la mediación del narrador, está presente y se hace oír en el texto. Alvar Núñez se conmueve ante la desolación de la tierra, la destrucción que dejan tras ellos los

\footnotetext{
${ }^{12}$ Ambos términos provienen de Beatriz Pastor (1988) en Discursos narrativos de la conquista de América.
} 
conquistadores, la desesperación de los indígenas que prefieren dejarse morir antes de sufrir la inhumanidad de la esclavitud. Cabeza de Vaca facilita que los indígenas reconozcan la diferencia entre un "cristiano" de verdad, es decir, quien los trata humanamente (él mismo) y los otros "cristianos", los conquistadores de Nueva Galicia, que los reducen a esclavitud y los torturan.

Sin embargo, el que enjuicie ese tipo de conquista no significa necesariamente que no la apoye. A pesar de su defensa de los indios y de darles la palabra para que puedan expresar su punto de vista, el alférez andaluz no logra deshacerse totalmente de su eurocentrismo. No preconiza éste la libertad de los indígenas, sino más bien una mayor libertad, dentro siempre de un marco de sumisión. El proyecto de conquista de Cabeza de Vaca adquiere una variante cristiana; se está muy lejos de cuestionar la superioridad de la religión católica sobre las creencias indígenas y de poner en duda el derecho de los europeos a conquistar y colonizar el continente. Su aspiración se plantea como necesaria y viable:

Dios nuestro señor por su infinita misericordia quiera que en los días de Vuestra Magestad y debaxo de vuestro poder y señorío, estas gentes vengan a ser verdaderamente y con entera voluntad subjetas al Verdadero Señor que los crió y redimió. Lo qual tenemos por cierto que assí será, y que Vuestra Majestad ha de ser él que lo ha de poner en effecto (que no será tan diffícil de hazer) porque dos mil leguas que anduuimos por tierra y por la mar en las varcas, y otros diez meses que después de salidos de captiuos, sin parar, anduuimos por la tierra, no hallamos sacrificios ni ydolatría (Cabeza de Vaca, 1992: 306).

Se hace difícil, de este modo, en la obra de Cabeza de Vaca, reconocer tanto un cuestionamiento de la conquista como tal, así como un desacato frontal de cara al discurso oficial. A pesar de que él se considera como cautivo a lo largo de ocho años, hemos visto que en determinados momentos, Núñez dispone de un elevado grado de autoridad y libertad, que alcanza uno de sus puntos álgidos precisamente al final de su periplo, cuando ve a sus compatriotas y da gracias a Dios 
por sacarles de tan "triste y miserable cautiverio". Cabe plantearse si esta identificación que tanto proclama responde a los intereses que guiaron al andaluz a dirigir su relato al rey con la intención de conseguir el favor real, algo que obtiene al lograr los títulos de Adelantado, Gobernador y Capitán General del Río de la Plata.

Para José Rabasa (1995: 183) los Naufragios son "una de las más acabadas escrituras de alguien que 'entonces' estuvo 'allá' y 'ahora' lo cuenta desde 'acá'”. Pupo-Walker (1987: 518, énfasis mío) afirma que: "una inspección detenida del material biográfico sobre y en torno a Cabeza de Vaca no revela, en ningún momento un desacuerdo significativo, entre las líneas generales de su pensamiento y el marco de valores e instituciones que consolidó la Corona española en el siglo xvI". Juan Francisco Maura (1995: 188, énfasis mío), por su parte, señala que, como hace Beatriz Pastor, es más fácil identificarse con el defensor de los indios que con el conquistador, afirmando con contundencia que Alvar Núñez nunca llegó a demostrar su imagen anticonquistadora fuera de los textos.

Es cierto, Alvar Núñez Cabeza de Vaca, como individuo de fuera de los textos, nacido en Jerez de la Frontera y que escribió una relación de sus experiencias en América, puede que se aleje de la cordial visión integradora que se le ha querido otorgar. Aunque, por otro lado, su condición de ex cautivo y las prebendas que seguramente pretendía obtener con su relación, le obligaran a mantener gran cautela en cuanto al grado de apego que muestra respecto a sus captores indígenas. Como en el caso de Cervantes, nunca sabremos a ciencia cierta lo que realmente estas personas de carne y hueso vivieron en sus cautiverios, y la imagen que de éstos quedó grabada en su memoria. Ambos nos legaron magníficos monumentos textuales de la cautividad, repletos de ambigüedades y silencios que ahora nos toca interpretar.

Resulta innegable que el personaje de papel "Cabeza de Vaca" que él mismo crea, a pesar de sus matices e intereses, destila un indudable cariño hacia los indígenas y el mundo americano. El Cabeza de Vaca no de fuera de los textos, sino de dentro de ellos, al emerger de su cautiverio, no es el mismo de ocho años atrás. Ha compartido y apreciado los alimentos de América, incluso los más sorprendentes; conoce desde dentro las prácticas chamánicas, ha vivido largo tiempo entre los in- 
dígenas a quienes ha sabido conocer y apreciar. Al cabo de su cautiverio, consciente de ello o no, disidente $\mathrm{u}$ oficialista, conquistador o aindiado, la figura de Alvar Núñez Cabeza de Vaca se alza como la de uno de los precursores del mestizaje cultural que va a constituir la esencia misma de la identidad hispanoamericana.

\section{Bibliografía}

Anderson-Imbert, Enrique (1970), "Historia de la literatura hispanoamericana", en vol. I. La Colonia, Holt, Chicago.

Arrom, José Juan (1983), “Gonzalo Fernández de Oviedo, relator de episodios y narrador de naufragios", en Casa de las Américas, vol 24-141, pp.114-123.

Bhabha, Homi (1994), The Location of Culture, Routledge, Nueva York. (1983), "Difference, Discrimination and the Discourse of Colonialism", en The Politics of Theory, University of Essex Press, Colchester.

Cabeza de Vaca, Alvar Núñez (1992), Los naufragios, Enrique PupoWalker (ed.), Castalia, Madrid.

Concha, Jaime (1986), “Réquiem por el 'buen cautivo'”, en Hispamérica, vol. 15-45, pp. 3-5.

Cortés, Hernán (1993), Cartas de relación, Ángel Delgado Gómez (ed.), Castalia, Madrid.

Fernández de Oviedo y Gonzalo Valdés (1959), Historia general y natural de las indias, Ediciones Atlas, Madrid.

Goldberg, Harriet (1997), "Cannibalism in Iberian Narrative: the Dark Side of Gastronomy", en Bulletin of Hispanic Studies, vol. 74, pp. 107-122.

Herren, Ricardo (1992), Indios carapálidas, Planeta, Madrid.

Invernizzi Santa Cruz, Lucía (1986), "Naufragios e infortunios: discurso que transforma fracasos en triunfos", en Dispositio, vol. 11, 28-29, pp. 99-111.

Lagmanovich, David (1978), "Los Naufragios de Alvar Núñez como construcción narrativa", en Kentucky Romance Quarterly, vol. 25, pp. 22-37. 
Maravall, José Antonio (1975), La cultura del barroco, Ariel, Barcelona. Maura, Francisco (1995), "Veracidad en los Naufragios. La técnica narrativa de Alvar Núñez Cabeza de Vaca", en Revista Iberoamericana, vol. 61, pp. 187-195.

Molloy, Sylvia (1987), “Alteridad y reconocimiento en los Naufragios de Alvar Núñez Cabeza de Vaca", Nueva Revista de Filología Hispánica, vol. 35-24, pp. 25-449.

Nanfito, Jackeline (1994), “Cabeza de Vaca's Naufragios y Comentarios: the Journey Motif in the Chronicle of the Indies", en Revista de Estudios Hispánicos, vol. 21, pp. 179-187.

O'Gorman, Edmundo (1946), Sucesos y diálogos de la Nueva España de Gonzalo Fernández de Oviedo y Valdés, Ediciones de la Universidad Nacional Autónoma de México.

Pastor, Beatriz (1988), Discursos narrativos de la conquista: mitificación y emergencia, Ediciones del Norte, Hanover. (1989), "Silence and Writing: the History of the Conquest", en 1492-1992: Re/discovering Colonial Writing, René Jara y Nicholas Spadaccini (eds.), The Prisma Institute, Minneapolis, pp. 121163.

Pratt, Mary Louise (1986), "Scratches on the Face of the Country; or What Mr. Barrow Saw in the Land of the Bushman", en Race, Writing and Difference, Henry Louis Gates (ed.), University of Chicago Press, Chicago, pp. 138-62.

Pupo-Walker, Enrique (1990), "Notas para la caracterización de un texto seminal: los Naufragios de Alvar Núñez Cabeza de Vaca", en Nueva Revista de Filología Hispánica, vol. 38, pp. 163-196.

(1987), "Pesquisas para una nueva lectura de los Naufragios de Alvar Núñez Cabeza de Vaca", en Revista Iberoamericana, vol. 140, pp. 517-539.

Rabasa, José (1995), “De la allegoresis etnográfica en los Naufragios de Alvar Núñez Cabeza de Vaca", en Revista Iberoamericana, vol. 171, pp. 175-185.

Rivera Martínez, Edgardo (1993), “Singularidad y carácter de los Naufragios de Alvar Núñez Cabeza de Vaca", en Revista de Crítica Literaria Hispanoamericana, vol. 19, pp. 301-315. 
Spitta, Silvia (1993), "Chamanismo y cristiandad: una lectura de la lógica intercultural de los Naufragios de Cabeza de Vaca", en Revista de Crítica Literaria Hispanoamericana, vol. 19, pp. 317-330. Tapia, Andrés de (1939), "Relación de Andrés de Tapia", en Crónicas de la conquista de México, Agustín Yánez (ed.), Ediciones de la Universidad Nacional Autónoma de México.

Fecha de recepción: julio de 2007

Fecha de aprobación: agosto de 2007 